www.jmscr.igmpublication.org

Impact Factor 5.84

Index Copernicus Value: 71.58

ISSN (e)-2347-176x ISSN (p) 2455-0450

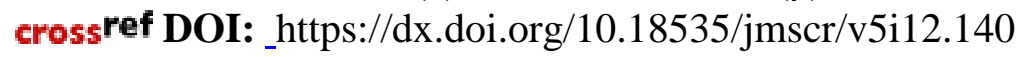

Journal Of Medical Science And Clinical Research

\title{
Adenocarcinoma Lung with a Central Presentation
}

\author{
Authors \\ Dr Lakshmanan ${ }^{1}$, Dr Anandha Kumar ${ }^{2}$, Prof. Dr L.Stanley ${ }^{3}$, Prof. Dr D. Rajasekaran ${ }^{4}$ \\ ${ }^{1}$ Postgraduate, ${ }^{2}$ Assistant Professor, ${ }^{3,4}$ Professor \\ Department of General Medicine, \\ Chettinad Hospital and Research Institute, Chennai
}

\begin{abstract}
Non small cell carcinoma comprises $80 \%$ of lung cancer. Of which adenocarcinoma is the commonest. It is the most frequently diagnosed subtype in women, as well as in non-smokers, and their symptoms usually correlate with the disease. It is largely peripheral in location. Here we report an unusual case of centrally located adenocarcinoma in a 65year old female in the late stages of disease with few symptoms.

Keywords: Lung cancer, Adenocarcinoma, Central location, Lepidic pattern.
\end{abstract}

\section{Introduction}

The World Health Organization (WHO) defines lung cancer as tumors arising from the respiratory epithelium (bronchi, bronchioles, and alveoli). The WHO classification system divides epithelial lung cancer into small cell and non small cell carcinomas. Non-small cell lung carcinoma constitutes Squamous cell carcinoma, adenocarcinoma and large cell carcinoma. Adenocarcinoma has become the most frequent histologic subtype of lung cancer. Adenocarcinoma incidence has been increasing and replaced squamous carcinoma. In adenocarcinoma, the histopathological patterns are acinar, papillary, solid and Lepidic. A subtype of adenocarcinomais Bronchioloalveolar carcinoma (BAC) The definition of bronchiolveolar carcinoma requires that the tumor have a pure lepidic growth pattern without evidence of stromal, vascular, or pleural invasion. However, there was a significant modification to the WHO classification system is the discontinuation of the terms

bronchioloalveolar carcinoma.

\section{Case Report}

65 year female presented with Complaints of breathlessness for the past 4 months with a gradual onset, progressed from grade 3 to grade 4and was aggravated on exertion. There was no history of orthopnoea or PND. Cardiac cause of breathlessness were ruled out. She also had complaints of hoarseness of voice since 4 months. Along with dry cough. She was recently diagnosed as a diabetic and a hypertensive and treated accordingly.

On examination she was conscious, oriented, afebrile and obese. Her vitals were stable. Her oxygen saturation was $97 \%$ at room air. Examination of the respiratory system showed features consistent with a left sided pleural effusion; other system were normal. Blood investigations were normal except for a raised ESR. 


\section{JMSCR Vol||05||Issue||12||Page 32142-32144||December}

Chest radiograph was suggestive ofa raised left hemi diaphragm and left pleural effusion. Biochemical analysis showed an exudative pleural effusion, cytology was negative for malignant cells.

A Contrast enhanced CT imaging of chest was performed and it revealed large heterogenous enhancing mass lesion in left parahilar region, encasing the left upper lobe bronchus with collapse of left upper and lingular lobe. Encasing of left pulmonary artery was also seen.
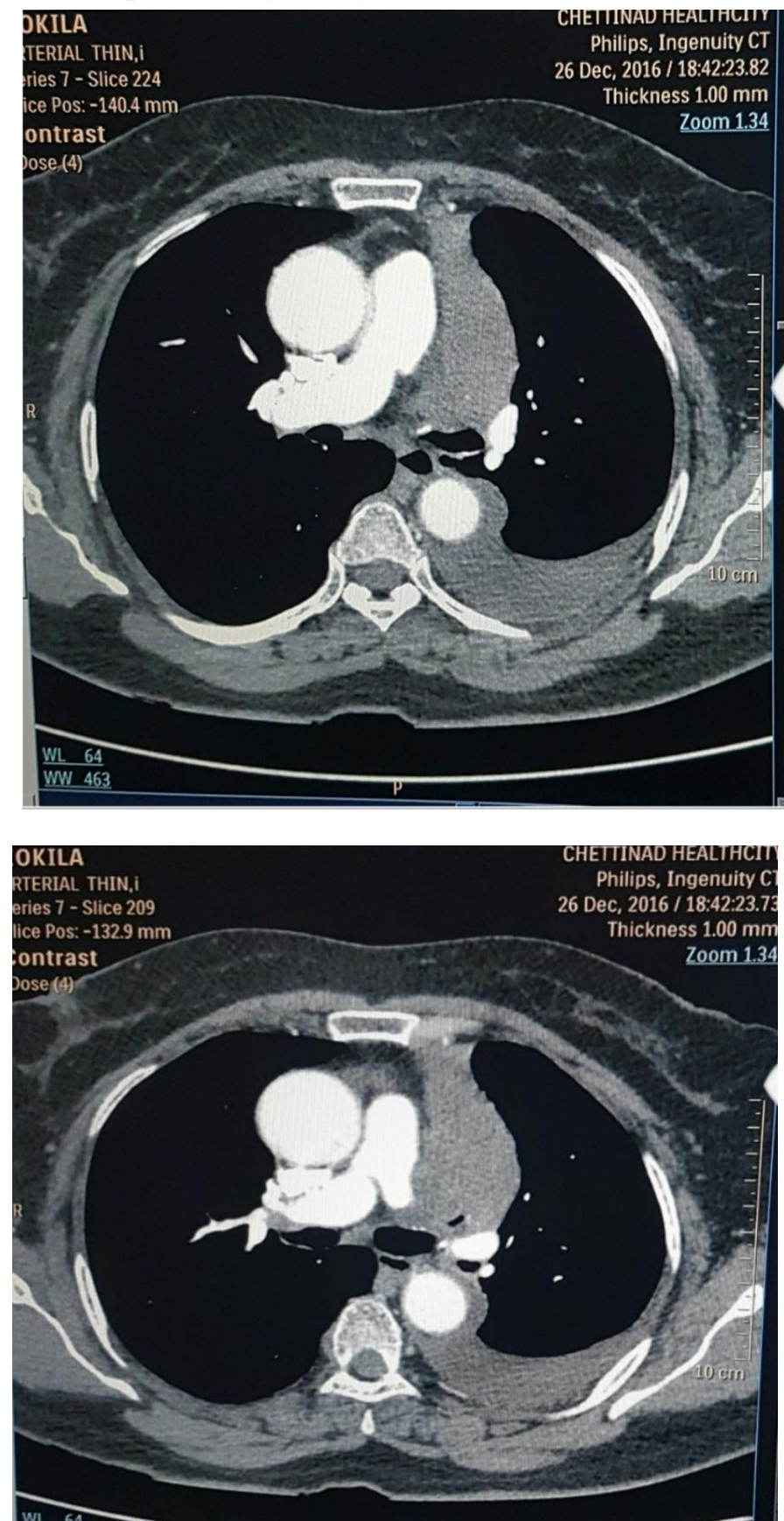

Medially, the lesion is invading the mediastinal pleura, pericardium and aorta pulmonary window and left main bronchus. The mass is abutting the Left atrium, Left pulmonary vein and Aortic arch. Moderate pleural effusion on left was present. Subcentimetric left lower paratracheal and para aortic lymph nodes were present.

The patient underwent a Bronchoscopy guided biopsy.

Histopathological examination of the tissue revealed Non Small Cell Carcinoma of Lung; Positive for malignancy and Adenocarcinoma with lepidic pattern. Thus, the patient was diagnosed to have Adenocarcinoma with lepidic pattern.
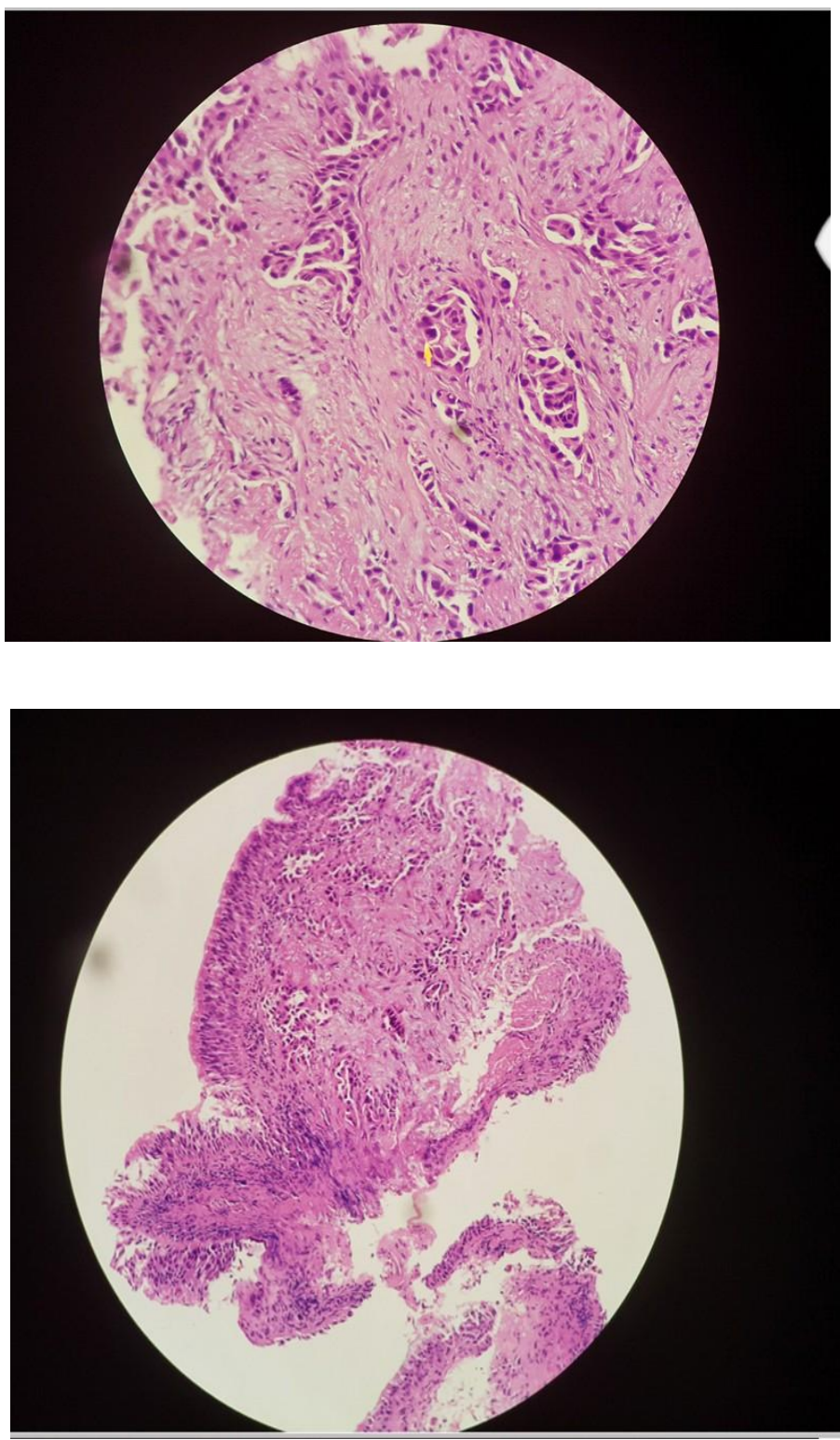

In view of advanced disease, the patient and her relatives opted for palliative care. 


\section{Discussion}

In this case thoughthe patient presented within 3 months of symptoms, the palliative treatment was the only possibilitydue to its central presentation and access issues.

Pulmonary adenocarcinoma generally occurs in peripheral lung tissue, however, central lesions accounted for $13.3 \%$ of all patients undergoing surgical resection. The treatment varies based on the location.

Peripherally situated adenocarcinoma enables wedge resection of suitably small lesions, while adenocarcinoma in central locations usually required lobectomy, regardless of tumor size or opacity. If more than lobectomy was needed, mediastinal lymph node evaluation (dissection or sampling) was routinely performed at the same time in most central tumor resections resulting in higher nodal counts for greater accuracy of staging. Higher malignant potential may be ascribed to central adenocarcinoma, given its more invasive attributes.

\section{Conclusion}

In early (stage I) disease, the prognosis is comparatively worse for central adenocarcinoma, owing to significant micromorphologic differences in central and peripheral tumors. The management of NSCLC has undergone major change in the past decade. The centrally located pulmonary adenocarcinoma is detected in an advanced stage for many patients.

Tumors that are centrally located or have demonstrated invasion into the pulmonary hila or mediastinal structures needs special consideration.

\section{References}

1. Travis WD, Brambilla E, Noguchi M, et al. International association for the study of lung cancer/american thoracic society/ european respiratory society international multidisciplinary classify-cation of lung adenocarcinoma [PubMed]
2. Kadota K, Villena-Vargas J, Yoshizawa A, et al. Prognostic significance of adenocarcinoma in situ, minimally invasive adenocarcinoma, and nonmucinouslepidic predominant invasive adenocarcinoma of the lung [PubMed]

3. Brambilla E, Travis WD, Colby TV, Corrin B, Shimosato Y. The new World Health Organization Classification of lung tumours. Eur Respir.

4. Mountain CF. A new international staging system for lung cancer. Chest. 1986;89:225-233. [PubMed]

5. Yesner R. Classification of lung cancer histology. N Engl J Med. 1985;312:652653.[PubMed] 